\title{
Association between maternal cannabis use and birth outcomes: an observational study
}

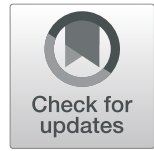

\author{
Camilla A. Michalski ${ }^{1 *}$ (D), Rayjean J. Hung ${ }^{1,2}$, Ryan A. Seeto ${ }^{2}$, Cindy-Lee Dennis ${ }^{3,4}$, Jennifer D. Brooks ${ }^{1}$, \\ Joanna Henderson ${ }^{5,6}$, Robert Levitan ${ }^{5,6,7}$, Stephen J. Lye ${ }^{2}$, Stephen G. Matthews ${ }^{2,7,8,9}$ and Julia A. Knight ${ }^{1,2}$
}

\begin{abstract}
Background: As cannabis consumption is increasing globally, including among pregnant women, there is a critical need to understand the effects of cannabis on fetal development and birth outcomes. We had two objectives: to determine 1) the factors associated with self-reported cannabis use in the pre/early-pregnancy period, and 2) whether cannabis use is associated with low birth weight, preterm birth, or small size for gestational age (GA) infants.
\end{abstract}

Methods: Maternal questionnaire and birth outcome data was gathered from 2229 women and 1778 singleton infants in the Ontario Birth Study, a hospital-based prospective cohort study (2013-2019). Women self-reported cannabis use within 3 months of learning their pregnancy status. Multivariable linear and logistic regression was conducted to 1) identify factors associated with cannabis use, and 2) determine the associations between cannabis use with the selected birth outcomes.

Results: Cannabis use increased in the cohort over time. Women who reported cannabis use $(N=216)$ were more likely to be younger and more likely to use alcohol, tobacco, and prescription pain medication, although most did not. These women had infants born at lower average birth weights and had 2.0 times the odds of being small for GA (95\% confidence interval: $1.3,3.3$ ) after multivariable adjustment for socioeconomic factors and other substance use.

Conclusion: Our results suggest that women who use cannabis around the time of conception have higher odds of having infants that are small for gestational age. Targeted clinical messaging may be most applicable to women actively trying to conceive.

Keywords: Cannabis, Marijuana, Epidemiology, Canada, Women, Pregnancy, Small for gestational age, Birth weight

\section{Background}

Cannabis use is rising globally, and has more than doubled among Canadians between 1985 and 2015 [1]. It is also cited as the most commonly used illicit substance during pregnancy $[2,3]$. Studies have shown cannabis use to be highest in early first trimester, followed by substantial drop-off as the pregnancy progresses $[4,5]$. As consumption gains social acceptance, and in light of

\footnotetext{
*Correspondence: camillamichalski@gmail.com

${ }^{1}$ Dalla Lana School of Public Health, University of Toronto, Toronto, Ontario, Canada

Full list of author information is available at the end of the article
}

evidence that suggests endocannabinoid involvement in early reproductive events [6], pregnant women and their children stand to benefit from targeted research concerning birth outcome effects of prenatal cannabis use.

While some existing studies have already presented a link between maternal cannabis use and adverse birth outcomes such as low birth weight and preterm birth, others continue to report no association [7, 8]. One of the biggest challenges in this research area lies in isolating the independent association between cannabis use and birth outcomes, given that many cannabis users use alcohol and tobacco concurrently [3].

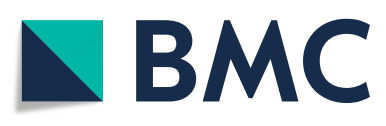

$\mathrm{BMC}$ (c) The Author(s). 2020 Open Access This article is licensed under a Creative Commons Attribution 4.0 International License, which permits use, sharing, adaptation, distribution and reproduction in any medium or format, as long as you give appropriate credit to the original author(s) and the source, provide a link to the Creative Commons licence, and indicate if changes were made. The images or other third party material in this article are included in the article's Creative Commons licence, unless indicated otherwise in a credit line to the material. If material is not included in the article's Creative Commons licence and your intended use is not permitted by statutory regulation or exceeds the permitted use, you will need to obtain permission directly from the copyright holder. To view a copy of this licence, visit http://creativecommons.org/licenses/by/4.0/ The Creative Commons Public Domain Dedication waiver (http://creativecommons.org/publicdomain/zero/1.0/) applies to the data made available in this article, unless otherwise stated in a credit line to the data. 
As such, a homogeneous study population with low rates of concurrent substance use could better isolate the association in question. Utilizing such a study population, our research endeavour had two main objectives: first, to determine which factors are associated with maternal cannabis use in the pre/early-pregnancy period, and second, to analyze the association between cannabis use during this period with the following birth outcomes: low birthweight, preterm birth, and small size for gestational age (GA).

\section{Methods}

\section{OBS study design}

The study was conducted using data from the Ontario Birth Study (OBS), an ongoing prospective pregnancy and birth cohort study established at Mount Sinai Hospital, Toronto, Canada. Eligible participants included women 18 years of age or older within their first or early second trimester of pregnancy ( $\leq 17$ weeks GA). Between January 2013 and June 2019, 6950 women were approached for recruitment at antenatal clinics at Mount Sinai, of which 2973 (43\%) consented to participate. Twenty-four subsequently withdrew, leaving 2949 women in the current cohort.

In the OBS, the collection of biological samples, lifestyle questionnaires (LSQs), and clinical data is integrated with routine clinical care. LSQs are collected at three time points and can be completed electronically or on paper. The first, LSQ1, is usually administered between 12 and 16 weeks of gestation, LSQ2 between 24 and 32 weeks of gestation, and LSQ3 between 6 and 10 weeks postpartum. Additional information concerning the study cohort can be found elsewhere [9]. The OBS has been approved by Mount Sinai's Research Ethics Board and all participants have provided informed written consent (REB \#11-0321-E).

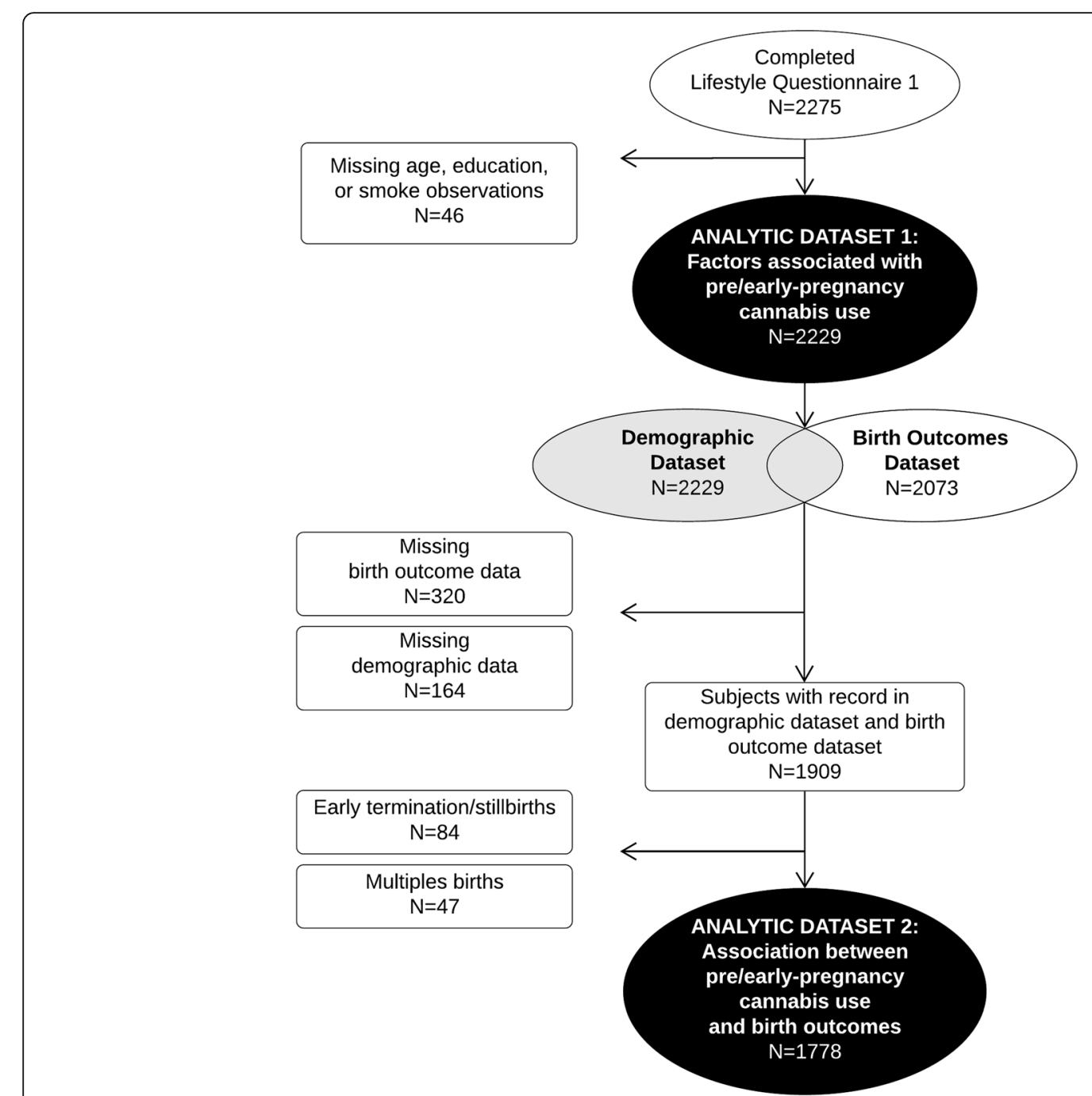

Fig. 1 Flowchart of exclusion criteria applied to create analytic datasets 


\section{Analytic datasets}

Of the 2949 women in the cohort, LSQ1 was completed and entered into the database for 2275 women at the time of data extraction (June 2019). Maternal age was missing for six participants and they were excluded. Observations with missing education $(N=19)$ or tobacco smoking measures $(N=21)$ were also excluded because they produced empty cells when cross-tabulated with pre/early-pregnancy cannabis use (Fig. 1). The final sample available for this analysis was 2229 women.

For the birth outcome models, this dataset $(N=2229)$ was then merged with birth outcome hospital records $(N=2073)$. Of these, 1778 observations were singleton, live births with corresponding maternal LSQ1 data; 5 observations were missing gestational age, and 3 were missing birthweight which were excluded from the corresponding regression analyses.

\section{Cannabis use}

Pre-pregnancy cannabis use was identified in LSQ1 with the following prompt, "In the 3 months before you knew you were pregnant, did you use any of the following drugs on your own without a doctor's prescription?" If "marijuana or hashish" was one of the options selected, then the participant was designated a pre/early-pregnancy cannabis user. If not selected, the participant was designated a non-cannabis user. One woman did not select "marijuana or hashish" for this question but reported using Nabilone (a synthetic cannabinoid) as a medication within 3 months of learning she was pregnant, and she was included as a pre/early-pregnancy cannabis user. This participant did not report continued use during pregnancy. No other participants reported using cannabis as a medication.

\section{Birth outcomes}

Pregnancy outcome information was derived from clinical data collected from hospital records. Stillbirth and twin pregnancies were excluded from analyses of birth outcomes. Separate regression models were created based on four outcome measures: birth weight (continuous), low birth weight (low/not low), preterm birth (preterm/term), and small size for GA (small/not small).

Low birth weight was defined as a birth weight less than $2500 \mathrm{~g}$ [10]. Preterm birth was defined as a live birth before 37 weeks of pregnancy. Small size for GA was defined as having a sex- and GA- specific birth weight less than the 10th percentile of the most recently published Canadian population-based reference group [11].

\section{Covariates}

Covariates were chosen for model inclusion based on factors identified in the literature as being associated with either cannabis use or fetal development and birth outcomes. All multivariable regression models included age, year of
LSQ1 completion, pre-pregnancy body mass index (BMI), household income, education, ethnicity, alcohol use, tobacco use, anxiety or depression symptoms, prescription anti-depressant use, and prescription pain medication use. Notably, smaller ethnicity categories had to be collapsed into coarser groups due to issues with convergence. Birth outcome models also adjusted for infant sex and GA.

Depression symptoms were measured using the 2-item Patient Health Questionnaire (PHQ-2), and anxiety symptoms were measured using the 2-item Generalized Anxiety Disorder scale (GAD-2). A score greater than or equal to 3 on either PHQ-2 or GAD-2 was used to define depression and/or anxiety for the covariate measure. Meta-analyses of validation studies suggested a sensitivity of 0.89 (95\% CI $0.81-0.95)$ and specificity of 0.76 (95\% CI 0.70-0.81) for PHQ-2, and 0.76 (95\% CI $0.55-$ 0.89 ) and 0.81 (95\% CI 0.60-0.92) for GAD-2 [12, 13].

Prescription antidepressant and pain medication use was identified through the following prompts, "In the past six months, have you taken any prescription medicines? Please include only medicines that have been prescribed by your doctor." If "depression/anxiety medications" or "pain medications" were selected, then the participant was considered a user of the respective medication.

\section{Statistical analyses}

Descriptive summary statistics were calculated for each variable. To determine a trend in cannabis use over time, a Cochran-Armitage test was conducted. In total, five outcomes were analyzed: pre/early-pregnancy cannabis use (yes/no) for the first study objective, and birth weight (continuous), low birth weight (low/not low), preterm birth (preterm/term), and small size for GA (small/not small) for the second study objective. Linear regression was used for the continuous birth weight outcome, and the average birth weight of infants born to cannabis-using mothers (compared to non-cannabis-using mothers, in grams) was reported. Logistic regression was used for binary outcomes, and odds ratios (ORs) were reported.

Missing observations were kept in the model and only dropped if they produced an empty cell when crosstabulated with the outcome of interest. For prepregnancy BMI $(N=122)$ and household income $(N=$ 147), the median was imputed for the missing values. The multivariable regression models were run with robust cluster analysis, such that if an individual participated in the OBS for more than one pregnancy, these pregnancies were clustered together $(N=53)$.

To further rule out the potential effects of other substance use, three sensitivity analyses were conducted: [1] participants reporting smoking tobacco during pregnancy were excluded, [2] participants reporting consuming any alcohol during pregnancy were excluded, and [3] participants reporting either 
smoking tobacco or consuming alcohol during pregnancy were excluded. For [2] and [3], additional analyses also excluded observations with missing alcohol consumption information.

Data processing and analyses were performed using Stata version 14.0 (Stata Corporation, College Station, TX).

\section{Results}

\section{Study population}

Among the 2229 women included for analysis of factors associated with pre/early-pregnancy cannabis use, the mean age (standard deviation) was 33.7(3.8) years at baseline, and pre-pregnancy BMI was 23.4(4.6). The majority $(74.2 \%)$ of the cohort reported a household income of more than $\$ 100,000$ per year, with $41.1 \%$ reporting a graduate degree. About half of the cohort reported nonJewish European ethnicity (53.8\%). Jewish ethnicity was the third most commonly reported at $14.9 \%$ (many women with Jewish heritage seek care at Mount Sinai Hospital due to historical ties to the Jewish community).

With respect to cannabis measures, 216 (9.7\%) women reported use in the three months before knowing they were pregnant. On average, women reported finding out they were pregnant $4.30( \pm 1.30)$ weeks into gestation.

With respect to birth outcomes, $51.2 \%$ of infants were born male. Low-weight births and preterm births had a prevalence of $4.8 \%(N=85)$ and $5.9 \%(N=105)$, respectively. Small for GA births were more common with a prevalence of $9.6 \%(N=170)$. Additional demographic factors and their distributions are reported in Table 1.

Factors associated with pre/early-pregnancy cannabis use Women had lower odds of reporting cannabis use in the pre/early-pregnancy period if they were older (OR: 0.92, 95\% CI: $0.89,0.97$ for every additional year of age), and higher odds if they had completed the questionnaire in more recent years (OR: 1.19, 95\% CI: 1.10, 1.29 per calendar year) (Table 2). A Cochran-Armitage test analyzing changes in prevalence of use over time also suggested a significant $1.4 \%$ increase in self-reported pre/early-pregnancy cannabis use per year (Fig. 2). Women reporting Jewish ethnicity had marginally higher odds of reporting cannabis use compared to those reporting non-Jewish European ethnicity (OR: 1.50, 95\% CI: 0.99, 2.26), whereas women reporting Asian ethnicities had comparatively lower odds (OR: 0.46, 95\% CI: 0.25, 0.87). Compared to the lowest household income level $(\leq \$ 99,999)$, those that reported the highest income $(\geq \$ 200,000)$ exhibited 0.47 times the odds of reporting pre/early-pregnancy cannabis use (95\% CI: 0.30, 0.80).

Women who reported not having consumed any alcohol in the year before pregnancy had 0.21 times the odds of reporting cannabis use (95\% CI: 0.08, 0.51), whereas those that reported consuming alcohol both before and during pregnancy exhibited 3.13 times the odds of reporting pre/ early-pregnancy cannabis use (95\% CI: $2.07,4.72)$ compared to women who consumed alcohol only before pregnancy (the majority of women). Compared to non-smokers, women who smoked tobacco before pregnancy only, and those that smoked tobacco during pregnancy exhibited higher odds of pre/early-pregnancy cannabis use than nonsmokers (OR: 4.07, 95\% CI: 2.71, 6.13; and OR: 4.73, 95\% CI: $1.79,12.48$, respectively). Taking prescription pain medication was also associated with pre/early-pregnancy cannabis use (OR: 2.08, 95\% CI: 1.16, 3.71). Pre-pregnancy BMI, education level, anxiety and/or depression symptoms, and antidepressant use were not associated with pre/earlypregnancy cannabis use in this population.

\section{Association between cannabis use and birth outcomes}

Infants born to mothers reporting pre/early-pregnancy cannabis use weighed $86 \mathrm{~g}$ less on average than those born to mothers reporting no pre/early-pregnancy cannabis use (95\% CI: - 155, - 17) (Table 3). No association was found with low birth weight as a binary measure, nor preterm birth. Offspring of women who reported pre/early-pregnancy cannabis use had 2.03 times the odds of being small for GA (95\% CI: 1.25, 3.31) (Table 3).

Sensitivity analyses with differing population exclusions based on tobacco and alcohol consumption during pregnancy suggested that the magnitude and direction of the associations remained generally consistent. In short, the magnitude and direction of the findings stayed consistent after the removal of these observations. In all analyses, women who consumed cannabis had small for GA infants, ranging from an odds ratio of 1.83 to 2.14 . Women who consumed cannabis also generally had lower birth weight infants, ranging from 64.8 to $98.3 \mathrm{~g}$ lower, although some results (i.e. analyses where current smokers were removed) became marginally statistically insignificant (see Supplementary Table 1).

\section{Discussion}

We found that pre/early-pregnancy cannabis use increased in our study conducted before and after the legalization of recreational use in Canada. In this study, which followed over 2000 women, we found that those who used cannabis were younger and were more likely to drink alcohol, smoke tobacco, and use prescription pain medication. Reported use was lower in women in the highest income category but did not differ across other income categories. With respect to birth outcomes, we found that women who reported cannabis use in the 3 months prior to learning they were pregnant had infants born at lower average birth weights, and these infants had higher odds of being small for GA.

With respect to factors associated with cannabis use, our findings fall in line with those in comparable studies. 
Table 2 Odds ratios for factors associated with pre-pregnancy cannabis use $(\mathrm{N}=2229,2013-2019)$

\begin{tabular}{|c|c|c|c|c|}
\hline & $\begin{array}{c}\text { Cannabis Users } \\
\mathbf{N}=\mathbf{2 1 6}\end{array}$ & $\begin{array}{c}\text { Non-Users } \\
N=2,013\end{array}$ & $\begin{array}{l}\text { Adjusted } \\
\text { Odds Ratio }\end{array}$ & $95 \% \mathrm{Cl}$ \\
\hline & $\operatorname{Mean}(s d)$ & Mean(sd) & & \\
\hline \multirow[t]{2}{*}{ Age } & $32.6(3.8)$ & $33.8(3.8)$ & 0.92 & $0.89,0.97$ \\
\hline & $N(\%)$ & $N(\%)$ & & \\
\hline \multicolumn{5}{|l|}{ Year } \\
\hline Per year & & & 1.19 & $1.10,1.29$ \\
\hline \multicolumn{5}{|l|}{ Ethnicity } \\
\hline Non-Jewish European & $120(55.6)$ & $1079(53.6)$ & (ref) & - \\
\hline Jewish & $45(20.8)$ & $288(14.3)$ & 1.50 & $0.99,2.26$ \\
\hline Asian & $14(6.5)$ & $356(17.7)$ & 0.46 & $0.25,0.87$ \\
\hline Other & $37(17.3)$ & $290(14.4)$ & 1.26 & $0.82,1.92$ \\
\hline \multicolumn{5}{|l|}{ Income } \\
\hline$\leq 99,999$ & $54(25.0)$ & $375(18.6)$ & (ref) & - \\
\hline $100-149,900$ & $50(23.2)$ & $462(23.0)$ & 0.74 & $0.46,1.18$ \\
\hline $150-199,900$ & $70(32.4)$ & $575(28.5)$ & 0.92 & $0.60,1.41$ \\
\hline$\geq 200,000$ & $42(19.4)$ & 601 (29.9) & 0.47 & $0.30,0.80$ \\
\hline \multicolumn{5}{|l|}{ Missing } \\
\hline \multicolumn{5}{|l|}{ Education } \\
\hline <Bachelor's & $50(23.2)$ & $300(14.9)$ & 1.50 & $0.95,2.36$ \\
\hline Bachelor's & $86(39.8)$ & $877(43.6)$ & (ref) & - \\
\hline >Bachelor's & $80(37.0)$ & $836(41.5)$ & 1.06 & $0.75,1.49$ \\
\hline \multicolumn{5}{|l|}{ Pre-pregnancy BMI } \\
\hline$<18.5$ & $7(3.2)$ & $90(4.5)$ & 0.995 & $0.43,2.28$ \\
\hline $18.5-<25$ & $160(74.1)$ & $1324(71.2)$ & (ref) & - \\
\hline $25-<30$ & $32(14.8)$ & $331(16.4)$ & 0.80 & $0.52,1.24$ \\
\hline $30-<100$ & $17(7.9)$ & $158(7.9)$ & 0.76 & $0.42,1.40$ \\
\hline \multicolumn{5}{|l|}{ Alcohol Use } \\
\hline None & $5(2.3)$ & $245(12.2)$ & 0.21 & $0.08,0.51$ \\
\hline Before only & $166(76.9)$ & 1548 (76.9) & (ref) & - \\
\hline Before \& during & $42(19.4)$ & $144(7.2)$ & 3.13 & $2.07,4.72$ \\
\hline Missing & $3(1.4)$ & $76(3.8)$ & 0.54 & $0.16,1.85$ \\
\hline \multicolumn{5}{|l|}{ Tobacco Use } \\
\hline None & $158(73.2)$ & $1876(93.2)$ & (ref) & - \\
\hline Before only & $48(22.2)$ & $118(5.9)$ & 4.07 & $2.71,6.13$ \\
\hline Before \& during & $10(4.6)$ & $19(0.9)$ & 4.73 & $1.79,12.48$ \\
\hline \multicolumn{5}{|c|}{ Anxiety or Depression Symptoms } \\
\hline No & $188(87.0)$ & $1777(88.3)$ & (ref) & - \\
\hline Yes $^{\mathrm{b}}$ & $27(12.5)$ & $199(9.9)$ & 0.98 & $0.62,1.55$ \\
\hline Missing & $1(0.5)$ & $37(1.8)$ & 0.28 & $0.04,2.16$ \\
\hline \multicolumn{5}{|l|}{ Taking Rx Antidepressants } \\
\hline No & $185(85.7)$ & $1808(89.8)$ & (ref) & - \\
\hline Yes $^{c}$ & $26(12.0)$ & $123(6.1)$ & 1.52 & $0.91,2.52$ \\
\hline Missing & $5(2.3)$ & $82(4.1)$ & 0.44 & $0.05,4.07$ \\
\hline \multicolumn{5}{|l|}{ Taking Rx Pain Medication } \\
\hline No & $190(88.0)$ & 1849 (91.9) & (ref) & - \\
\hline$Y_{e s}^{c}$ & $19(8.8)$ & $78(3.9)$ & 2.08 & $1.16,3.71$ \\
\hline Missing & $7(3.2)$ & $86(4.3)$ & 1.52 & $0.21,11.21$ \\
\hline \multicolumn{5}{|c|}{$\begin{array}{l}\text { Abbreviations: } \mathrm{Cl} \text { : confidence interval; sd: standard deviation; BMI: body mass index; Rx: prescription; } \\
\text { a Adjusted odds ratios (ORs), } 95 \% \text { confidence intervals, and p-values are derived from one multivariable } \\
\text { logistic regression model with robust cluster analysis, adjusted for all variables listed in table. } \\
{ }^{b} \text { A score } \geq 3 \text { on either GAD-2 or PHQ-2 was used to indicate anxiety and/or depression symptoms. } \\
\text { cTaking prescription antidepressants/pain medication was recorded as "Yes" if taken in the three } \\
\text { months before or during pregnancy. }\end{array}$} \\
\hline
\end{tabular}




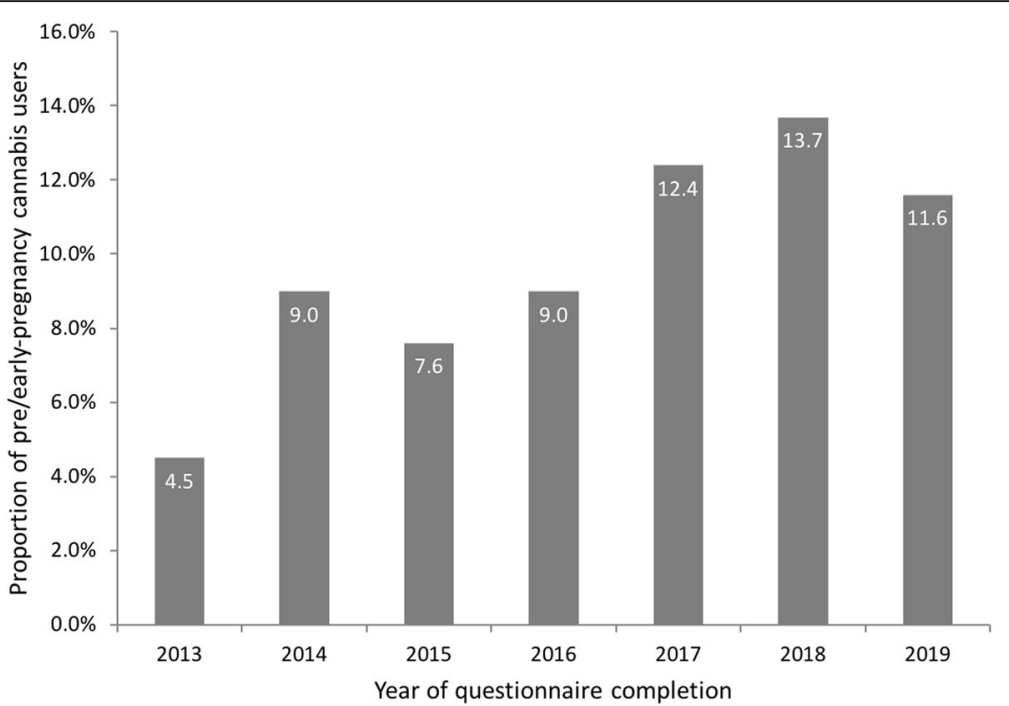

Fig. 2 Proportion of study participants reporting pre/early-pregnancy cannabis use, per year (2013-2019)

provider, we may have better minimized the risk of misclassification. The prevalence of pre/early-pregnancy use in our cohort (9.7\%) was similar to the prevalence of use $(10.0 \%)$ in women aged 25 to 44 years in Ontario in the 2012 Canadian Community Health Survey [24].

In terms of illicit substance use, only 50 women $(<5 \%)$ in our study reported use in the 3 months before

Table 3 Effect measures of maternal cannabis use on selected birth outcomes

\begin{tabular}{lll}
\hline Outcome & Coefficient & $95 \% \mathrm{Cl}$ \\
\hline Birth weight $^{\text {a }}$ (grams) $^{\text {Non-Users }}$ & & \\
Users & (ref) & \\
& -85.8 & $-154.6,-17.2$ \\
& Odds Ratio & $95 \% \mathrm{Cl}$
\end{tabular}

Low birth weight ${ }^{\text {a }}$

$\begin{array}{ll}\text { Non-Users } & \text { (ref) } \\ \text { Users } & 0.93\end{array}$

Preterm birth ${ }^{b}$

$\begin{array}{lll}\text { Non-Users } & \text { (ref) } & 0.62,2.57 \\ \text { Users } & 1.26 & \\ \text { Small size for GA } & & \\ \text { Non-Users } & \text { (ref) } & \mathbf{1 . 2 5 , 3 . 3 1} \\ \text { Users } & \mathbf{2 . 0 3} & \end{array}$

$N=1773$ for preterm birth model, $N=1770$ for birth weight and small size for GA models Abbreviations: $\mathrm{Cl}$ confidence interval, GA gestational age

${ }^{a}$ Continuous (linear) and binary (logistic) birth weight regression models with robust cluster analysis adjusted for infant sex, GA (continuous), pre/early-pregnancy cannabis use, year of LSQ1 completion, maternal age, ethnicity, education, income, pre-pregnancy BMI, alcohol use, tobacco use, anxiety/depression symptoms, antidepressant use, and pain medication use.

bPreterm birth and small for GA logistic regression models adjusted for infant sex, pre/early -pregnancy cannabis use, year of LSQ1 completion, maternal age, ethnicity, education, income, pre-pregnancy BMI, alcohol use, tobacco use, anxiety/ depression symptoms, antidepressant use, and pain medication use pregnancy, which was not associated with cannabis use $(p=0.63)$. General smoking rates were also lower among our cannabis-using population compared to other studies (73.2\% non-smokers among our cannabis users versus $29.7 \%$ among the Corsi et al. provincially representative population) [14]. These low rates of concurrent use helped further isolate the association in question. Our additional sensitivity analyses further strengthened our argument that concurrent tobacco use cannot explain all of the observed associations with cannabis.

Lastly, our study captured an early time point of cannabis use. As mentioned, previous studies have suggested that self-reported cannabis use is highest in the early first trimester, followed by substantial drop off as the pregnancy progresses [5]. Thus, our pre/early-pregnancy measure questioning participants about their cannabis use 3 months before learning their pregnancy status may be capturing a crucial window of high cannabis exposure, which other studies overlooked (of the 1778 women in the birth outcome models, only 10 reported using cannabis during pregnancy, 1510 reported no use, and 258 were missing a measure). It is possible that the associations we observed with the pre/early-pregnancy use period are due to under-reported use during pregnancy; the proportion of women reporting use during pregnancy in our study is lower than that reported in other studies [25].

There are a number of potential limitations that should be considered. Because our cannabis use measure was self-reported, its prevalence may be understated as some women who use cannabis may be misclassified as nonusers. Non-disclosure rates may especially affect observations that were collected before recreational cannabis use was legalized, when stigma was higher. This reduction in stigma surrounding use may also contribute to our finding 
that cannabis use increased over time. However, this misclassification would bias our findings towards the null, suggesting that the true association may actually be larger than the reported results. Urinalysis screenings were not available, although it is important to consider that no gold standard measure exists. Differing rates of excretion, metabolism, cannabinoid potency, and half-life times affect urinalysis accuracy [26]. In fact, El Marroun and colleagues (2011) showed substantial agreement between urinalyses and self-reported measures [26].

Our measure of cannabis use also did not take frequency, amount, or mode of delivery into account. While deeper insight into women's patterns of use could prove fruitful and help distinguish between light and heavy users, the variability in individual tolerance and cannabinoid concentrations poses significant barriers to the applicability of such measures. Regarding potential differences between different modes of consumption, data from the National Cannabis Study (2019) suggests that compared to men, Canadian women are much more likely to report any other mode of consumption other than smoking compared to men [27]. Deeper insights into the potential differences in risk between these different modes are warranted in light of growing trends in alternative modes of consumption, such as edibles and vaping.

\section{Conclusion}

We found that pre-pregnancy (before women knew that they were pregnant, which likely includes early pregnancy) cannabis use is associated with lower mean birth weight and increased odds of having an infant born small for GA. Targeted clinical messaging may be most applicable to women who are actively trying to conceive.

\section{Supplementary Information}

Supplementary information accompanies this paper at https://doi.org/10. 1186/s12884-020-03371-3.

Additional file 1: Supplementary Table 1: Effect measures of materna cannabis use on select birth outcomes with different population exclusion criteria applied.

\section{Abbreviations}

BMI: Body mass index; Cl: Confidence interval; GA: Gestational age; GAD-2: 2item Generalized Anxiety Disorder scale; LSQ: Lifestyle questionnaire; OBS: Ontario Birth Study; OR: Odds ratio; PHQ-2: 2-item Patient Health Questionnaire; SD: Standard deviation

\section{Acknowledgements}

The authors acknowledge the contribution and support of Kim Foshay and other Ontario Birth Study Team members. In addition, we thank and are extremely grateful to all the study participants.

\section{Authors' contributions}

CAM: Conducted all data cleaning and analysis and drafted manuscript. RJH: Contributions to the conception and design of the work, acquisition, analysis, and interpretation of data, and critical revision of the manuscript. RAS: Responsible for data acquisition and contributions to data cleaning and interpretation and critical revision of the manuscript. CLD: Contributions to data interpretation and critical revision of the manuscript. JDB: Contributions to data interpretation and critical revision of the manuscript. JH: Contributions to data interpretation and critical revision of the manuscript. RL: Contributions to the conception and design of the work and data interpretation and critical revision of the manuscript. SJL: Contributions to the conception and design of the work, data acquisition, data interpretation, and critical revision of the manuscript. SGM: Contributions to the conception and design of the work, data acquisition, data interpretation, and critical revision of the manuscript. JAK: Responsible for the conception of the research objective, contributed to overall design and data acquisition, supervised data analysis, contributed to data interpretation and drafting of manuscript. All authors approved the final version of the manuscript and agree to be accountable for all aspects of the work in ensuring that questions related to the accuracy or integrity of any part of the work are appropriately investigated and resolved.

\section{Funding}

This work was supported by: Canadian Institutes of Health Research [CU3 160313] (to JAK) Canadian Institutes of Health Research [FDN 143262] (to SJL) Cameron Holcombe Wilson Research Chair (to RL)

Lunenfeld-Tanenbaum Research Institute and the Department of Obstetrics and Gynecology, Sinai Health System

Mount Sinai Hospital Foundation

The funding bodies played no role in the study design, collection of data, analyses, interpretation, nor writing of the manuscript.

\section{Availability of data and materials}

The participant data used to support the findings of this study were from the Ontario Birth Study and are not freely available to respect the confidentiality of the participants, ensure data integrity, and avoid scientific overlap between projects. Approval for use of the data requires a research proposal subject to review by the Ontario Birth Study Steering Committee, as well as approval by institutional research ethics boards. Additional details are available on the study website at www.ontariobirthstudy.com

Ethics approval and consent to participate

The OBS has been approved by Mount Sinai's Research Ethics Board (REB approval \#11-0321-E). All study participants provided informed written consent. Data access for this project was approved by the Ontario Birth Study Steering Committee.

\section{Consent for publication}

Not applicable, as no data is reported on an individual basis.

\section{Competing interests}

The authors of this paper have nothing to disclose.

\section{Author details}

${ }^{1}$ Dalla Lana School of Public Health, University of Toronto, Toronto, Ontario, Canada. ${ }^{2}$ Lunenfeld-Tanenbaum Research Institute, Sinai Health System, Toronto, Ontario, Canada. 'awrence S Bloomberg Faculty of Nursing, University of Toronto, Toronto, Ontario, Canada. ${ }^{4}$ St. Michael's Hospital, Toronto, Ontario, Canada. ${ }^{5}$ Centre for Addiction and Mental Health, Toronto, Ontario, Canada. ${ }^{6}$ Department of Psychiatry, University of Toronto, Toronto, Ontario, Canada. ${ }^{7}$ Department of Physiology, University of Toronto, Toronto, Ontario, Canada. ${ }^{8}$ Department of Obstetrics and Gynecology, University of Toronto, Toronto, Ontario, Canada. ${ }^{9}$ Department of Medicine, University of Toronto, Toronto, Ontario, Canada.

Received: 28 May 2020 Accepted: 28 October 2020

Published online: 11 December 2020

\section{References}

1. Rotermann M, Macdonald R. Analysis of trends in the prevalence of cannabis use in Canada, 1985 to 2015. Health Rep [Internet]. 2018;(82):10-20.

2. Schauberger CW, Newbury EJ, Colburn JM, Al-hamadani M. Prevalence of illicit drug use in pregnant women in a Wisconsin private practice setting. Am J Obstet Gynecol [Internet]. 2014;211(3):255.e1-4. https://doi.org/10. 1016/j.ajog.2014.03.023. 
3. Metz TD, Stickrath EH. Marijuana use in pregnancy and lactation: a review of the evidence. Am J Obstet Gynecol [Internet]. 2015;213(6):761-78 https:// doi.org/10.1016/j.ajog.2015.05.025.

4. Badowski S, Smith G. Cannabis use in pregnancy and postpartum. Canadian Fam Phys [Internet]. 2020;66(2):98-103.

5. Alshaarawy $\mathrm{O}$, Anthony JC. Cannabis use among women of reproductive age in the United States: 2002-2017. Addict Behav [Internet]. 2019;99: 106082. https://doi.org/10.1016/j.addbeh.2019.106082.

6. Schneider M. Cannabis use in pregnancy and early life and its consequences: animal models. Eur Arch Psychiatry Clin Neurosci [Internet]. 2009;259(7):383-93. https://doi.org/10.1007/s00406-009-0026-0.

7. Stickrath E. Marijuana use in pregnancy: an updated look at marijuana use and its impact on pregnancy. Clin Obstet Gynecol [Internet]. 2019;62(1):185-90. https://doi.org/10.1097/GRF.0000000000000415.

8. Thompson R, DeJong K, Lo J. Marijuana use in pregnancy: a review. Obstet Gynecol Surv [Internet]. 2019;74(7):16-22. https://doi.org/10.1097/OGX. 0000000000000685 .

9. Anderson LN, Knight JA, Hung RJ, Hewko SL, Seeto RA, Alison MM, et al. The Ontario birth study: a prospective pregnancy cohort study integrating perinatal research into clinical care. Paediatr Perinat Epidemiol [Internet]. 2018:32(3):290-301. https://doi.org/10.1111/ppe.12473.

10. World Health Organization, editor. ICD-10: international statistical classification of diseases and related health problems: tenth revision. 2nd ed: World Health Organization; 2004. https://apps.who.int/iris/handle/10665/42980.

11. Kramer M, Platt R, Wen S, Joseph K, Allen A, Abrahamowicz M, et al. A new and improved population-based Canadian reference for birth weight for gestational age. Pediatr Int. 2001;108(2):E35. https:/doi.org/10.1542/peds.108.2.e35.

12. Mitchell AJ, Yadegarfar M, Gill J, Stubbs B. Case finding and screening clinical utility of the patient health questionnaire (PHQ-9 and PHQ-2) for depression in primary care: a diagnostic meta- analysis of 40 studies. BJPSych Open [Internet]. 2016;2(2):127-38. https://doi.org/10.1192/bjpo.bp. 115.001685.

13. Plummer F, Sc M, Manea L, Sc M, Psych MRC, Trepel D, et al. Screening for anxiety disorders with the GAD-7 and GAD-2: a systematic review and diagnostic meta-analysis. Gen Hosp Psychiatry [Internet]. 2016;39:24-31. https://doi.org/10.1016/j.genhosppsych.2015.11.005.

14. Corsi DJ. Trends and correlates of cannabis use in pregnancy: a populationbased study in Ontario, Canada from 2012 to 2017. Can J Public Health [Internet]. 2019;110(1):76-84. https://doi.org/10.17269/s41997-018-0148-0.

15. Corsi DJ, Walsh L, Weiss D, Hsu H, El-chaar D, Hawken S, et al. Association between self-reported prenatal cannabis use and maternal, perinatal, and neonatal outcomes. JAMA [Internet]. 2019;322(2):145-52. https://doi.org/10. 1001/jama.2019.8734.

16. Luke S, Hutcheon J, Kendall T. Cannabis use in pregnancy in British Columbia and selected birth outcomes. J Obstet Gynaecol Canada [Internet]. 2019;41(9):1311-7. https://doi.org/10.1016/j.jogc.2018.11.014.

17. Hutchings DE, Martin BR, Gamagaris Z, Miller N, Fico T. Plasma concentrations of delta-9-tetrahydrocannabinol in dams and fetuses following acute or multiple prenatal dosing in rats. Life Sci [Internet]. 1989: 44(11):697-701. https://doi.org/10.1016/0024-3205(89)90380-9.

18. Little $B B$, VanBeveren $T$. Placental transfer of selected substances of abuse. Semin Perinatol [lnternet]. 1996;20(2):147-53. https://doi.org/10.1016/s01460005(96)80082-6.

19. Fernandez-Ruiz JJ, Berrendero F, Hernandez ML, Romero J, Ramos JA. Role of endocannabinoids in brain development. Life Sci [Internet]. 1999;65(6-7): 725-36. https://doi.org/10.1016/s0024-3205(99)00295-7.

20. Harkany T, Keimpema E, Barabas K, Mulder J. Endocannabinoid functions controlling neuronal specification during brain development. Mol Cell Endocsrinol [nternet]. 2008:55:S84-90. https:/doi.org/10.1016/.mce.2008.02.011.

21. Costa MA. The endocannabinoid system: a novel player in human placentation. Reprod Toxicol [Internet]. 2016;61:58-67. https://doi.org/10. 1016/j.reprotox.2016.03.002

22. El Marroun $H$, Tiemeier $H$, Steegers EAP, Jaddoe WW, Hofman A, Verhulst FC, et al. Intrauterine cannabis exposure affects fetal growth trajectories: the generation R study. J Am Acad Child Adolesc Psychiatry [Internet]. 2009;48(12): 1173-81 Available from: https://doi.org/10.1097/CHI.0b013e3181bfa8ee.

23. Education in Canada. Key results from the 2016 Census [Internet]. p. 2017. Available from: https:/www150.statcan.gc.ca/n1/daily-quotidien/171129/ dq171129a-eng.htm.

24. Statistics Canada 13-610, Cannabis Stats Hub, Table 13-1004-65-01, modified Feb. 5, 2018.
25. Moore DG, Turner JD, Parrott AC, Goodwin JE, Fulton SE, Min MO, et al. During pregnancy, recreational drug-using women stop taking ecstasy and reduce alcohol consumption, but continue to smoke tobacco and cannabis: initial findings from the development and infancy study. J Psychopharmacol [Internet]. 2010;24(9):1403-10. https://doi.org/10.1177/0269881109348165.

26. El Marroun $\mathrm{H}$, Tiemeier $\mathrm{H}$, Jaddoe $\mathrm{WW}$, Hofman A, Verhulst FC. Agreement between maternal cannabis use during pregnancy according to self-report and urinalysis in a population-based cohort: the generation R study. Eur Addict Res [Internet]. 2011;17(1):37-43. https://doi.org/10.1159/000320550.

27. Canada S. National Cannabis Survey, second quarter 2019. Ottawa: Statistics Canada's The Daily; 2019. p. 18. Report No.: 11-001-X. https://www150. statcan.gc.ca/n1/pub/13-610-x/13-610-x2018001-eng.htm.

\section{Publisher's Note}

Springer Nature remains neutral with regard to jurisdictional claims in published maps and institutional affiliations.
Ready to submit your research? Choose BMC and benefit from:

- fast, convenient online submission

- thorough peer review by experienced researchers in your field

- rapid publication on acceptance

- support for research data, including large and complex data types

- gold Open Access which fosters wider collaboration and increased citations

- maximum visibility for your research: over $100 \mathrm{M}$ website views per year

At BMC, research is always in progress.

Learn more biomedcentral.com/submissions 